\title{
The Construction of Brand Culture Based on Corporate Culture
}

\author{
Yuekun Yang \\ School of Law and Public Administration, Jiangsu Polytechnic University \\ Changzhou 213164, China \\ E-mail: yyk@jpu.edu.cn
}

\begin{abstract}
Brand culture is an extension and identification as well as an important part of corporate culture. As the base of brand culture, corporate culture exerts an influence on the establishment of brand culture. Its internal function helps to improve the participation degree of the main body of brand culture construction and its external function helps to improve the popularity of the carrier of brand culture construction. In addition, developing and expanding the core idea of corporate culture helps to improve the loyalty of the object of brand culture construction.
\end{abstract}

Keywords: Brand, Brand culture, Corporate culture

Corporate culture is a general term for management ideas and methods, group consciousness, values and behavior standards with enterprises' own characteristics formed in production and business operation and widely accepted and followed by staff. Brand culture is an extension and identification as well as an important part of corporate culture. Excellent corporate culture helps to construct distinctive brand culture.

\section{The Connotation of Brand Culture}

Brand culture refers to the combination of some elements which help to identify and distinguish the products or services of a seller or sellers, including their names, nouns, logos, symbols and designs, cultural traits depositing in such a combination of elements and all cultural phenomena in the operation of these products or services as well as the totality of the interest cognition, emotional attributes, cultural traditions and individual images represented by these cultural traits and phenomena. Guided by market, brand culture aims at achieving the maximization of enterprises' market profits and consumers' value by establishing common values and behavior standards based on the amalgamation of the value of consumers and enterprises and the objectives of cultural amalgamation. Three issues call for attention in brand culture: first is brand popularity, that is, enterprises have brand culture orientation and convey relevant information to target consumers with certain transmission tools based on their analysis on consumers' demands, hence forming the social influences of brand culture; second is brand reputation, that is, consumers have brand culture associations based on their experiences and finally form comprehensive evaluation on brand culture and establish brand culture images. Third is brand loyalty, that is, enterprises try to maintain consumers' loyalty to their brands through constant brand relationship management.

\section{The Internal Relationship between Brand Culture and Corporate Culture}

As an important part of corporate culture, brand culture is its extension and identification. Meanwhile, as the base for brand culture, corporate culture influences its establishment as well.

\subsection{Brand Culture Being the Extension of Corporate Culture}

First of all, a brand is the carrier of corporate culture. Corporate culture is not only an enterprise's essence in brand creation but its ideas, wills, behavior standards and group styles reflected all through the process of brand operation. Since corporate culture, especially the core values and operation psychology in it, is invisible, instead of in an enterprise's external form, they have to be manifested in a brand's characteristics and services which are the very core of brand culture. Therefore, only with the help of brands will the vision be expanded to the market in corporate culture in order to enhance the internal cohesion and the external competitive power and finally to convert cultural effects into market effects as well as economic benefits.

Second, brand culture is an important part of corporate culture. Neither corporate culture nor brand culture can be separate from enterprises' products and operation, therefore, they have to serve enterprises' development and follow their strategies. In brand logos and packages, brand material culture is an reflection of enterprise material culture; in production engineering, sales process and modes of service, brand behavioral culture is an reflection of enterprise behavioral culture; in brand quality and orientation, brand ideological culture reflects the values that enterprises hold about clients and embodies their affection for the brands of their products or services, hence a reflection of enterprise spiritual culture. Therefore, brand culture should be an identification and external manifestation of corporate culture. 
Third, brand culture is the destination of corporate culture. Responsible for the transmission of aesthetics, brand culture influences consumers' philosophy of life and values. However, it can not only rely on external transmission because its connotation lies in corporate culture. Aiming at promoting and developing corporate culture, brand culture should conform to the idea of corporate culture in its external transmission process. Accordingly, brand culture can exert profound influences on corporate culture in its operation while the achievements of corporate culture need to be manifested in a market-oriented form in brand culture.

\subsection{Corporate Culture Being the Base for Brand Culture}

First, corporate culture is the soul of a brand. According to Davidson's "Brand Iceberg Theory" (1997), the logo and the symbol of a brand take up only $15 \%$ of the whole while the iceberg part taking up $85 \%$ reveals the values, intelligence and culture of the brand actually. It is culture that endows a brand with its charms since the culture embodied in a brand is special, high-grade and unique. Just like any product without culture, any enterprise without culture will not live long. With products as the material basis and corporate culture as the spiritual power of a brand, a brand will have more profound connotation as a result of its interaction with corporate culture. Only by absorbing unique corporate culture and manifesting it with profound cultural details will a brand have its own soul and connotation and satisfy consumers' psychological demands and values orientation. Consequently, corporate culture is not only able to improve a brand's reputation and popularity but to improve consumers' loyalty to it.

Second, corporate culture is the connotation and details of brand culture. Chinese brand name expert Feng Ai claims that it is quite necessary to create special cultural images or cultural consumption value for one's own brand and to create cultural connotation with consumption value besides its national backgrounds and traditional culture when establishing a brand. Although corporate culture cannot impose on consumers directly, all ideas and spirits claimed in it can be reflected in the quality, performance and services of products and have indirect influences on consumers through the consumption process. By exerting influences on its internal staff, corporate culture produces cultural brands or display brand culture. Accordingly, the brand culture purchased by the target consumers is enterprise strength and corporate culture carried by certain brand. Therefore, corporate culture is the basis for the survival and development of brand culture as well as the most central details of an enterprise's brand value.

Third, corporate culture influences the establishment of brand culture. The construction of brand culture should be conducted with the guidance of corporate culture. Therefore, corporate culture will determine the characteristics of a brand to some degree, hence determining the satisfaction degree of the target consumers feel about the specific brand. Meanwhile, corporate culture expands its vision to the whole cultural field all over the society through its brand or brand culture. Actually, a brand represents the image of an enterprise as well as the brand itself in the eyes of consumers. Enterprise image is the unification of corporate culture and brand culture in that favorable brand image reflects favorable corporate culture while excellent corporate culture cultivates excellent brand culture. Therefore, corporate culture has dual ultimate missions, that is, shaping a complete internal corporate cultural system as well as creating brands with humanity and cultural details in order to improve brands spiritually and materially and to strengthen their vitality.

\section{Constructing Distinctive Brand Culture}

It is well known that a brand's value is far beyond the material level but lies in the spiritual cultural connotation it embodies. Brand culture, centering on the shaping and introduction of brand individuality and spirits, aiming at endowing a brand with cultural characteristics and human connotations, making the spirits manifested in the brand accepted by the target consumers through a variety of sales strategies and activities and forming a loyal consumer group. As a kind of rational and self-conscious culture, corporate culture has its specific internal and external functions. It will help the construction of distinctive brand culture to exert the functions of corporate culture.

\subsection{Exerting the internal Function of Corporate Culture to Improve the Participation Degree of the Subject of Brand Culture Construction}

The internal function of corporate culture is mainly manifested as follows: first, corporate culture has a cohesive function due to which enterprise staff is united with their common values and spiritual ideas, hence having pride and sense of mission as well as sense of identity and belonging for their enterprises. As a result, powerful centripetal force and cohesiveness exist in enterprises, producing high group effects. Second, corporate culture has self-coordination function. Just like a kind of lubricant, it helps to coordinate interpersonal relationship and create harmonious atmosphere. This invisible hand helps to convert enterprises' common goals into their staff's self-conscious actions, to promote harmonious internal relationship and to improve their efficiency by 
automatically coordinating the staff's psychology and behavior. Third, corporate culture has stimulating function. It is like a kind of lubricant or even much more like a force pump to provide enterprises with energy which produces an invisible spiritual driving force to stimulate the staff's enthusiasm and creativity to work hard for their enterprises willingly. Fourth, corporate culture has restrictive and regulatory function. Like an invisible rope, it has restriction and regulation on every member's ideas and behavior. Instead of those rational and elastic restrictions, these invisible soft ones have more powerful, lasting and profound effects compared with those visible tough restrictions.

With enterprise staff as the subject of brand culture construction, distinctive enterprise spirits and images can be established and first-class brand products or services can be created only by constantly improving the staff's comprehensive quality. Man orientation is a new pattern for modern corporate culture, whose core values include respecting, caring people and realizing people's value. Therefore, the exertion of the internal function of corporate culture means attaching great importance to people's value and respecting, caring, depending on, understanding, uniting, cultivating and developing people to the largest degree to fully encourage enterprise staff's enthusiasm for brand culture construction.

\subsection{Exerting the External Function of Corporate Culture to Improve the Popularity of the Carrier of Brand Culture Construction}

The external function of corporate culture is mainly manifested in its radiating and penetrating functions. Like dynamic yeast or even a radiation source with great heat power, it plays a radiating role in the whole society as well as in both the internal and external parts of enterprises.

With brand products or services as the carrier of brand culture construction, consumers choose their cultural grades as well as functions and quality when purchasing certain products or services. When exerting its role in brands, corporate culture can help to expand brand culture and establish favorable social images by manifesting the level of brand design, expanding the connotation and extension of brand culture, constructing brand sales network, constructing brand service modes and so on. Enterprise image is a comprehensive reflection of enterprises' values and spirits, a powerful weapon for enterprises' development strategies depending on culture as well as the symbol and fruit of corporate culture. The richer cultural details and the more profound human colors are embodied in enterprise image, the greater impact and influence will be produced at market. With a favorable reputation and image formed among target consumers, brand products or services will help enterprises to retain regular customers, to increase customer delivered value and to gain permanent loyalty as well as to form barriers to competition and to raise their rivals' cost to attract customers. As a result, the exertion of the external function of corporate culture means establishing favorable enterprise images among people by transmitting corporate culture in addition to supplying their products, services, public relations and advertisements. In this way, brand reputation and popularity will be improved accordingly.

\subsection{Promoting and Developing the Core Idea of Corporate Culture to Improve the Loyalty of the Object of Brand Culture Construction}

Although it is conducted, constructed and developed by enterprises, brand culture has to conform to consumers' individual demands, hence dominated by consumption. In other words, if consumers accept a brand and have psychological response with its brand culture, they will purchase it naturally. Therefore, when constructing brand culture, consumers' inner world and individual demands must be considered and fulfilled. Besides, brand culture has to vary in accordance to the changes in consumers' demands. Only with constant innovation with the era will brand culture maintain its strong life force.

Consumers' psychological agreement is the object of brand culture construction. Just like products or services can satisfy people's basic demands, core ideas can satisfy people's spiritual demands and positive ideas can establish brands with profound connotations, hence guiding consumers' choice of products or services. With increasing physical similarities shared by products nowadays, it is brand that determines consumers' purchase decisions, in which an enterprise's core idea touches consumers' heart to the greatest degree. Deposited and condensed in corporate culture, core idea is extracted from enterprises' special practice, hence their spiritual wealth and motive force as well as the manifestation of their strength, profit and management essence. In spite of its invisibility, dynamic core idea can penetrate into every aspect of business operation. It will enhance consumers' favorable impressions and associations of brands and improve brand loyalty to promote and develop the core idea of corporate culture and endow brands with special and exclusive connotation and individuality. It is shown in practice that those cultural ideas pursuing individuality, cultural grades, characteristics of the era and national details, including profound cultural connation, humanism and ethics and connecting strategic objectives with social benefits and consumers' demands will appeal to consumers. Therefore, unique brand culture with 
individuality and connotation must go along with corresponding cultural ideas.

\section{Conclusion}

Lacking in vitality, those brands without cultural nourishment will lose the test of market economy, so will such enterprises. Therefore, enterprises should attach greater importance to their own cultural nourishment and cultivation. The construction of brand culture should be rooted in the understanding of corporate culture. The deeper understanding they have on corporate culture, the easier they grasp the true essence and key to it. Future competition will be competition in brand, or more like that in the culture they represent. Excellent corporate culture will not only improve enterprise management level but also be the spiritual pillar for brand culture connotation. Only by converting invisible cultural value into visible brand value and cultural wealth into capital for their competition and pursuing higher added value and market value with their brand culture connotation depending on their advantages in corporate culture will they develop better brands and win the market competition finally.

\section{References}

Bai, Guang. (2002). Brand Culture: Cases of Chinese and Foreign Brands. China Modern Economic Publishing House.

Chen, Chunhua. (2002). Corporate Culture Management. South China University of Technology Press.

Crainer, Stuart., \& Dearlove, Des. Translated by Xiang, dong. (2003). Branding: How to Cultivate a Brand. Shanxi Normal University Press.

Huang, Lei \& Liu, Shuhui. (2007). A Comparative Research between Brand Culture and Corporate Culture. Modern Ecnomics.

Liu, Guangming. (2004). Corporate Culture. Economic Management Press.

Satoshi Akutsu \& Ishida, Shigeru. Translated by Han, zhong. (2005). Context branding. Shanghai People Press.

Yang, Yuekun. (2009). Corporate Culture Innovation: Spiritual Codes of Enterprise Innovation. China University of Mining and Technology Press.

Yu, Mingyang \& Yang, Fangping. (2005). Branding Course. Fudan Press.

Zhou, Zhaoqi, Hou, Longwen \& Xing, Hongping. (2002). Brand Culture: Cultural Meaning, Philosophical Idea and Manifestation of Commodities. Economic Management Press.

Zhu, Li. (2006). Research on Brand Culture Strategy. Economic Science Press.

Zhu, Li. (2008). An Interpretation of the Connotation of Brand Culture. Oriental Corporate Culture. 